\title{
SENTENCIA SOBRE UN CASO DE EXPOSICIÓN IMPRUDENTE AL DAÑO. UN ANÁLISIS DE SU EFECTO MODERADOR EN LA DETERMINACIÓN DEL QUANTUM INDEMNIZATORIO (CORTE DE APELACIONES DE ANTOFAGASTA)
}

\author{
Comentario de David Quintero Fuentes
}

Antofagasta, diez de enero de dos mil ocho.

VISTOS:

\section{EN CUANTO AL RECURSO DE CASACIÓN EN LA FORMA}

Que en esta causa Rol No 4.175-2005 del Tercer Juzgado Civil de esta ciudad, el día veinte de julio último, se dictó sentencia definitiva de primera instancia -como consta a fs. 178 y siguientes-, la que después de rechazar tachas interpuestas por la demandada en contra de dos testigos de la actora y una objeción de documentos deducida también por dicha parte, acogió con costas, la demanda de indemnización de perjuicios interpuesta por doña Mirla de la Estrella Guerra Rodríguez en contra de Empresas La Polar S.A., antes Sociedad Comercial Siglo XXI S.A., representada por su Gerente General Pablo Sergio Alcalde Saavedra.

En contra de este fallo, la parte demandada interpuso en lo principal de su presentación de fs. 195, recurso de casación en la forma, pidiendo se anule la sentencia recurrida y se proceda a dictar sentencia de reemplazo, rechazando la demanda, con costas.

Al fundar el recurso expresó que los vicios y o defectos que lo sustentan son los del $\mathrm{N}^{\circ} 5$ del artículo 768 del Código de Procedimiento Civil, en relación con los numerales 4 y 5 del artículo 170 del mismo Código, ya que el juez pronunció la sentencia con omisión de los fundamentos de derecho que le sirven de fundamento y de las leyes, con arreglo a las cuales se pronuncia el fallo.

Agrega que el juez de primer grado tras una inconducente transcripción de las deposiciones testimoniales, realizada entre los considerandos $4^{\circ}$ y $11^{\circ}$, dio por establecida la obligación delictual o cuasidelictual, sin citar consideraciones de derecho, alguna norma sustantiva, ni tampoco alguna de aquellas reguladoras de la prueba y valoró los supuestos perjuicios, resultando imposible saber cómo el juez determina cualquier tipo de acción u omisión, ni cómo valora la culpa ni la relación causal.

Añade que, además, el juez recurrido pronunció sentencia sin señalar y sin pronunciarse sobre las excepciones y alegaciones de su parte, conforme lo obliga el $\mathrm{N}^{\circ} 3$ del artículo 170 del código procedimental, lo que resulta muy grave ya que alegó variadas 
defensas como la eximición de responsabilidad por el hecho ajeno imposible de prevenir, la culpa de la propia víctima y la exposición temeraria al daño, de esta última.

Hizo valer también como fundamento del recurso la falta de decisión del asunto controvertido en cuanto debe comprender todas las acciones y excepciones hechas valer en el juicio -además de las mencionadas-, la aplicación preferente de ley especial, esto es, la Ley $\mathrm{N}^{\circ} 19.628$ sobre tratamiento de datos personales, infringiéndose así la obligación contenida en el numeral sexto del tantas veces aludido artículo 170.

Terminó manifestando que el juez sin valorar la prueba ni señalar los fundamentos de derecho ha condenado a una millonaria indemnización, con costas y, al no pronunciarse sobre las excepciones opuestas, lo ha dejado en la indefensión, causándole un perjuicio reparable sólo con la invalidación del fallo, debiendo dictarse sentencia de reemplazo que rechace la demanda interpuesta, con costas.

\section{CON LO RELACIONADO Y CONSIDERANDO:}

PRIMERO. Que el abogado don Gabriel Pumpin Valck, por la parte demandada, Empresas La Polar -antes Comercial Siglo XXI S.A.-, ha interpuesto recurso de casación en la forma en contra de la sentencia de primer grado dictada en esta causa, fundándolo en el artículo $768 \mathrm{~N}^{\circ} 5$ del Código de Procedimiento Civil, en relación con los numerales 4, 5 y 6 del artículo 170 del mismo código, esto es, en haber sido pronunciada la sentencia con omisión de consideraciones acerca de los fundamentos de derecho y de las leyes que fundan la parte resolutiva del fallo, sin pronunciarse sobre las excepciones y alegaciones de su parte, por lo que faltó la decisión del asunto controvertido, habiéndole provocado un perjuicio reparable sólo con la invalidación de la sentencia.

SEGUNDO. Que efectivamente, de una simple lectura del fallo que se cuestiona, se advierte una ausencia de fundamentos de derecho que permitan establecer la responsabilidad por la que se condena a la parte demandada y resulta evidente que el juez a quo no razonó en forma alguna sobre excepciones y alegaciones hechas valer por la misma.

TERCERO. Que sin embargo, no habiéndose causado a la recurrente perjuicio reparable sólo con la declaración de nulidad, en la medida que se interpuso recurso de apelación, fundado en los mismos y otros argumentos, de acuerdo a lo prescrito en el penúltimo inciso del artículo 768 del Código de Procedimiento Civil, se rechazará el recurso de casación en la forma que interpuso la parte demandante.

\section{EN CUANTO AL RECURSO DE APELACIÓN.}

\section{VISTOS:}

Se reproduce la sentencia en alzada, con las siguientes modificaciones: 
1. En el considerando primero se sustituye la palabra "ejecutada" por "demandada"; en el motivo segundo se reemplaza el término "ejecutante" por "demandante"; en el considerando tercero se sustituyen las voces "ejecutada" por "demandada" y "ejecutante" por "demandante" y en el motivo cuarto, se reemplaza la palabra "ejecutada” por "demandada".

2. En el mismo motivo tercero se reemplaza "expositiva" por "resolutiva".

3. Se eliminan los considerandos sexto, duodécimo, decimocuarto, decimoquinto y decimosexto.

\section{Y TENIENDO, ADEMÁS, PRESENTE:}

CUARTO. Que los fundamentos del recurso de apelación que interpuso la parte demandada, comprenden aquéllos que sustentaron el recurso de casación en la forma ya analizado, sin ser exactamente los mismos, habiendo pedido a esta Corte que revoque la sentencia impugnada y "en definitiva acoja la demanda principal en todas sus partes, con costas". (sic)

En cuanto a la objeción de documentos opuesta por la recurrente a fs. 219 de esta instancia.

QUINTO. Que a fs. 219 la parte recurrente, objetó documentos que acompañara la parte apelada, mediante presentación de fs. 217 , consistentes en copias de una carta de cobranzas, fechada en julio de 2007 y antecedentes clínicos de su representada, expresando que los documentos acompañados, llamados "Carta de cobranza" y "Solicitud de examen", los objeta por falta de integridad y falsedad, pues - respecto del primero-, no se especifica la naturaleza de la misma cobranza ni su efectividad, el hecho de estar pagado o pendiente, castigada o transferida, ni menos acredita la existencia de una obligación ni de los daños o perjuicios reclamados en autos y en cuanto a la solicitud, además de lo anterior agrega que no tiene mérito probatorio, pudo pedirse en cualquier estado del juicio y corresponde a una tardía fabricación de prueba, carente de todo valor probatorio.

Se confirió traslado a su contraparte, sin que éste fuera evacuado.

SEXTO. Que atendida la distinta naturaleza de los instrumentos de que se trata y que a las causales que se invocan, aparece que ellas se sustentan en apreciaciones acerca de su valor probatorio, la que constituye facultad privativa del tribunal, por lo que se rechazarán las dichas objeciones.

En cuanto a la decisión sobre las tachas que fuera apelada

SÉPTIMO. Que el fallo en alzada ha rechazado las inhabilidades opuestas por la demandada en contra de las testigos de la actora doña Ada Fabiola Guerra Muñoz y doña Marcela del Carmen Rivera Saavedra.

Que de las declaraciones de las referidas testigos, no se trasunta que a ellas les falte imparcialidad por tener en el pleito un interés directo o indirecto de tipo pecuniario 
ni se ha acreditado por hechos graves, que la amistad que puedan tener con quien las presenta las haga inhábiles, por lo que se confirmará la sentencia en alzada en cuanto a tal rechazo.

En cuanto a la decisión apelada sobre rechazo a objeción documental

OCTAVO. Que el recurrente impugna la decisión del tribunal a quo en cuanto éste rechazó la objeción que opusiera en el primer otrosí de respecto de "todos aquellos documentos acompañados por la demandante que no emanan de su parte, por corresponder a copias simples cuya autenticidad e integridad no le constan, sin perjuicio que no han sido reconocidos por sus otorgantes, por lo que carecen de todo valor probatorio en relación a su parte”.

NOVENO. Que se confirmará el rechazo del juez de la instancia, teniendo solamente presente para ello, la falta de precisión de los términos empleados por el incidentista, respecto de treinta y cuatro documentos de diversa naturaleza acompañados por la actora a su demanda, por lo que las causales invocadas no resultan atingentes a todos y cada uno de ellos, variando también la determinación de a quien corresponde la carga de la prueba, siendo en definitiva facultad exclusiva del tribunal, el ponderar el valor probatorio de los mismos.

\section{EN CUANTO AL FONDO.}

DÉCIMO. Que en esta causa, se persigue la responsabilidad civil extracontractual que tendría Empresas La Polar S.A., antes Comercial Siglo XXI S.A., en relación con daños sufridos por la actora doña Mirla Guerra Rodríguez, permitiendo que los costos de éstos sean soportados por la demandada, mediante la indemnización de perjuicios que reclama. Que siendo esta situación excepcional, han de reunirse ciertos requisitos para que ella tenga lugar, que constituyen sus supuestos de hecho: 1) El hecho voluntario; 2) La culpa o ilicitud; 3) El daño y, 4) La causalidad, por lo que nos referiremos a cada uno de ellos, analizando los antecedentes probatorios allegados al efecto.

UNDÉCIMO. En relación a la voluntariedad del hecho, se ha acreditado que el día 7 de diciembre de 2005, dependientas de la demandada no devolvieron la cédula de identidad a doña Mirla Guerra después que ella efectuara un pago correspondiente a su cuenta, en el establecimiento comercial que mantiene dicha empresa en esta ciudad, sin que tampoco la demandante requiriera la devolución de su documento identificatorio sino hasta el día siguiente, cuestión que fue aceptada por las partes.

Con posterioridad, el día 17 de diciembre de ese año, dependientas de la demandada hicieron uso de la referida cédula de identidad, adquiriendo con ella diversos productos que fueron incorporados como deudas en la cuenta de la demandante, lo que reconoce la empresa demandada en su contestación a fs. 34 -acápite 7 del Capítulo II de su contestación-, al aceptar que las dependientes imputadas se encuentran confesas, sin que tenga trascendencia alguna que se trate de trabajadoras part-time o de tiempo completo. 
Se encuentra acreditado además, que la actora ha sido requerida de pago insistentemente por la empresa, la que informó sus antecedentes como deudora morosa a DICOM EQUIFAX, pese a que ésta reclamó y puso en su conocimiento la situación producida, sin dejar de tener en vista que la demandada además, procedió a descontar de su remuneración, a doña Nissa Paola Morales Leiva sumas de dinero para imputarlas al valor de dichas adquisiciones, como se desprende de la copia de la declaración voluntaria que prestara esta persona el día 6 de septiembre del año 2005, que se encuentra signada con el número dentro de la carpeta que constituye la Custodia Corte $\mathrm{N}^{\circ} 157-07$, anexa a este expediente, carpeta en la que también aparece copia de la denuncia referida a estos hechos, que pusiera la demandante en la Fiscalía Local del Ministerio Público de esta ciudad, con fecha 8 de enero de 2005.

La voluntariedad de la demandada está claramente establecida por la omisión de controles que la empresa debió implementar, así como por la realización de los actos antedichos, en forma consciente e informada, lo que no se controvirtió en autos.

DUODÉCIMO. En relación con el elemento de la culpa o ilicitud, necesaria para que tenga lugar la responsabilidad extracontractual, es necesario detenerse en la definición especial de culpa, contenida en el artículo 44 del Código Civil, la que tiene sus orígenes en materia contractual, estando conteste la doctrina en que a falta de otra definición es ésta la que debe utilizarse pues, siendo genéricas las referencias a la culpa o negligencia en materia extracontractual, debe aplicarse a su respecto la regla del artículo 44 inciso segundo, la que señala que la culpa o descuido sin otra calificación, significa culpa o descuido leve, que se define como la falta de aquella diligencia y cuidado que los hombres emplean ordinariamente en sus negocios propios.

DECIMOTERCERO. Que en este caso, de acuerdo a lo expuesto, nos podríamos encontrar ante un caso de culpa por el hecho ajeno efectuado por personas que siendo capaces, la ley ha añadido a su responsabilidad personal la de quien ejerce autoridad sobre ellas, específicamente estaríamos ante la responsabilidad civil del empresario por el hecho de sus dependientes, pudiendo también estimarse -al tenor de los hechos expuestos en la demanda y en la contestación-, que la demandada tuviera que responder por el hecho propio, si se desprende de los hechos que la negligencia se ha producido en la parte organizacional de la empresa.

DECIMOCUARTO. Que de los antecedentes de esta causa, aparece que efectivamente dependientas de la demandada se apropiaron de la cédula de identidad que no restituyeron a la demandante después de cursar el pago e hicieron mal uso de ella, retirando especies de la tienda que fueron consignadas en la cuenta de la demandante como adquiridas por ella, sin que la demandada haya acreditado en esta causa que mantiene algún control respecto de los documentos que puedan quedar en sus dependencias, ni tampoco que exista algún sistema que impida que se cursen operaciones con cédulas bloqueadas, ya que resulta evidente que el 17 de diciembre de 2005, fecha de la compra fraudulenta que se consignara en la cuenta de la demandante -según consta 
de los detalles de cobranza expedidos por la demandada y guardados en custodia-, la cédula de identidad de doña Mirla Guerra estaba bloqueada, como lo comprueban los documentos signados con el numero 1 en la custodia $N^{\circ}$ 157-07 de esta Corte, que se tienen a la vista y el de fs. 96 y siguientes.

Por otra parte también ha quedado demostrado que la operación se pudo realizar sin que se contara con la tarjeta de la tienda que quedó en poder de la demandante, como se desprende del documento signado con el número 13 de la carpeta de custodia ya indicada, lo que también implica una deficiencia en el procedimiento de la empresa demandada.

Que por último, de los antecedentes también aparece que, mientras una unidad de la empresa descuenta a una de sus trabajadoras el valor correspondiente a las mercaderías que se atribuyeron como compradas por Mirla Guerra, una de cobranzas masivas, actuando a su nombre, le cobra a la demandante las mismas sumas de dinero, lo que repugna principios fundamentales de nuestro sistema jurídico e implica una organización defectuosa de la empresa, habiendo quedado establecida su culpa por hecho propio.

DECIMOQUINTO. El tercer elemento de la responsabilidad civil -el daño-, es un factor que la condiciona, estableciendo diferencia con el derecho penal, que en ciertos casos impone la responsabilidad sin exigir la concurrencia de un daño -delitos de peligro- y que castiga incluso la tentativa y el delito frustrado. En materia civil la acción de responsabilidad nace cuando el daño se manifiesta y comprende no sólo a perjuicios sufridos en un derecho, sino que también la lesión en un interés justo y legítimo. Sin embargo el daño no ha sido definido en nuestra legislación y según el Diccionario de la Lengua Española, se entiende por daño "el efecto de dañar o dañarse" y, por dañar "causar detrimento, perjuicio, menoscabo, dolor o molestia", habiéndosele definido como "la diferencia que existe, entre la situación en que se encuentra la víctima después del hecho por el cual se responde y, la situación en que hipotéticamente se encontraría si tal hecho no hubiere ocurrido.

DECIMOSEXTO. El daño así definido, se clasifica en dos grandes categorías: A. Daños materiales o patrimoniales y, B. Daños morales o extrapatrimoniales y, hablando el artículo 2329 del Código Civil de la indemnización de "todo daño", se concluye que la indemnización debe ser completa.

Habiéndose demandado en esta causa una suma de dinero sólo por concepto de daño moral, es preciso determinar si éste se da en la especie.

Este daño que según Alessandri, puede ser definido como "el dolor, pesar o molestia que sufre una persona en su sensibilidad física, o en sus sentimientos, creencias o afectos". Siendo éste un concepto un tanto difuso, cuyo desarrollo corresponde al derecho civil del último siglo, se le ha definido también como "todo aquel menoscabo no susceptible de avaluación pecuniaria", haciéndolo sinónimo de daño no patrimonial y expandiéndolo para cubrir intereses serios de la víctima, como son los atributos de la personalidad, las consecuencias que se siguen de los daños a la integridad física o a la muerte y a la calidad de vida en general. 
Cabe señalar también que la doctrina y la jurisprudencia, han establecido los principios que rigen la determinación del daño indemnizable, señalando que la indemnización debe ser completa, sólo comprende daños directos - lo que se refiere más bien a la causalidad-, que el daño debe ser lícito, cierto y no tratarse de un daño hipotético o sujeto a conjeturas, directo, previsible, debe ser probado -lo que rige sin limitaciones en el daño material, existiendo posiciones divididas a este respecto en relación con el daño moral.

DECIMOSÉPTIMO. Que los daños morales demandados en esta causa, en los términos expuestos, han quedado acreditados con las declaraciones de los testigos Margarita Soledad Fuenzalida Díaz, Ada Fabiola Guerra Muñoz, Marcela del Carmen Rivera Saavedra, Delma Roselia Ovando Sánchez y don Roberto Hugo Molina Miranda, quienes se encuentran contestes al referir los padecimientos que ha sufrido la actora por la traumática experiencia vivida, las alteraciones que se le han producido en su ánimo, las dificultades derivadas de la imposibilidad de acceso al crédito como consecuencia de estos hechos y, en general el deterioro de su calidad de vida, a lo que deben sumarse especialmente las declaraciones de la psicóloga doña Marcela Orieta Maya Véliz, reproducidas por este fallo, que da cuenta del estado depresivo que la ha afectado y de las alteraciones producidas en su vida, todas las que, junto a los documentos de custodia -desde el número 18 al 23-, demuestran que ha sufrido serios quebrantamientos en su salud, lo que indudablemente ha tenido como causa la situación producida con la empresa demandada.

Ello no pudo menos que producirse si de los mismos antecedentes aparece que es una persona de más de sesenta años, cumplidora de sus obligaciones, tanto así que mantenía sus antecedentes intachables, pese a la menguada renta que percibe, habiendo visto estropeada su calidad de vida por las fallas organizacionales de la empresa demandada.

DECIMOCTAVO. Que cabe ahora referirse a la causalidad -último elemento de la responsabilidad civil de acuerdo a lo que se ha dicho- la que supone que entre el hecho y el daño, exista una relación directa y necesaria, lo que significa que el hecho culpable sea condición necesaria del daño, de manera que eliminado hipotéticamente ese hecho, el daño no se habría producido. Este elemento constituye así la "condictio sine qua non" de la responsabilidad.

En el caso que nos ocupa, esta causalidad aparece en forma simple, ya que resulta evidente que la conducta de la empresa demandada ha ocasionado los daños alegados. Resultando atingentes las pruebas rendidas al respecto, se ha podido determinar que el daño sufrido por doña Mirla Rodríguez, es atribuible normativamente a las omisiones y acciones de la demandada.

DECIMONOVENO: Que así entonces, con los medios probatorios allegados a los autos, ha quedado establecida la responsabilidad de la demandada, quien omitió establecer los dispositivos organizacionales que la diligencia exige para evitar daños a sus clientes, no llevando a cabo el comportamiento que éstos tienen derecho a esperar, 
realizando además voluntariamente y con conocimiento de la situación que afectaba a la demandante, conductas positivas que acrecentaron el daño, por lo que -al no haber presentado prueba alguna en contrario-, ha de estarse a la regla general que establece el primer inciso del artículo 2329 del Código Civil, esto es, que todo daño que pueda imputarse a malicia o negligencia de otra persona, debe ser reparado por ésta.

VIGÉSIMO. Que en todo caso, para la apreciación y cuantificación del daño, habrá de analizarse si efectivamente, como lo sostiene la demandada, la demandante se expuso imprudentemente al daño, lo que permitiría reducir la obligación indemnizatoria de la demandada.

De los hechos acreditados en la causa, resulta evidente que doña Mirla Guerra Rodríguez, incurrió en falta de cuidado al no pedir en forma inmediata la devolución de su cédula de identidad o a lo menos, haberlo hecho durante el mismo día 7 de diciembre de 2005, ya que ésa es la conducta razonablemente exigible a una persona prudente. Sin embargo, cabe señalar que ello ocurre al comienzo de la secuencia de hechos dañosos, sin que tenga influencia en su devenir.

VIGÉSIMO PRIMERO. Que así entonces y estimándose que la víctima actuó con imprudencia, necesariamente habrá de disminuirse la indemnización a otorgar, cuyo monto se determinará en la parte resolutiva de este fallo.

Y VISTOS ADEMÁS, lo dispuesto en los artículos 186 y siguientes del Código de Procedimiento Civil, SE DECLARA:

I. Que SE RECHAZA el recurso de casación en la forma, deducido en lo principal de la presentación de fs. 195.

II. Que se rechaza la objeción de documentos opuesta por el apelante en esta instancia, a fs. 219.

III. Que SE CONFIRMA, sin costas del recurso, la sentencia apelada de fecha veinte de julio del año dos mil siete, con declaración que se condena a EMPRESAS LA POLAR S.A., antes COMERCIAL SIGLO XXI S.A., a pagar a doña Mirla de la Estrella Guerra Rodríguez, la suma de \$5.000.000 (cinco millones de pesos) por concepto de indemnización por daño moral.

Se deja constancia que se hizo uso de la facultad que contiene el artículo 82 del Código Orgánico de Tribunales.

Regístrese y devuélvase.

Redacción de la Ministro Titular Gabriela Soto Chandía.

Rol No 583-07 (Civil) 


\section{COMENTARIO}

El presente comentario se centrará sólo en uno de los aspectos relevantes de la sentencia referida, específicamente en el efecto reductor de la llamada culpa concurrente de la víctima en la determinación del quantum indemnizatorio. Esto puede resultar un tanto paradójico, ya que la sentencia apenas se pronuncia sobre el punto en cuestión, limitándose a expresar en el considerando vigésimo primero que estimándose que la víctima actuó con imprudencia, necesariamente habrá de disminuirse la indemnización a otorgar, cuyo monto se determinará en la parte resolutiva del fallo. En efecto, de acuerdo a lo dispuesto por el art. 2330 C.C., la apreciación del daño está sujeta a reducción si el que lo ha sufrido se expuso a él imprudentemente. Es de lamentar que no obstante los muchos casos en que nuestros tribunales hacen aplicación del aludido precepto legal, los jueces se limitan a dar por configurada la exposición imprudente al daño por parte de la víctima, sin indicar ni siquiera someramente los criterios que se han tenido en cuenta para proceder a la correspondiente rebaja del quantum indemnizatorio. Si bien el juzgador cuenta con un margen de discrecionalidad para proceder a la avaluación de los perjuicios, y muy especialmente en la apreciación del daño moral, ello no implica que los jueces no deban explicitar los criterios que han tenido a la vista para proceder a la rebaja, más allá de alusiones genéricas. Una actitud contraria da cuenta de un serio déficit argumentativo, que impide fundamentar adecuadamente la sentencia. Esto resulta particularmente importante, tanto para la víctima que ve reducida la cuantía de la indemnización y, por tanto, no ve reparado íntegramente el daño causado; y por otra parte, para el agente que debe responder de los perjuicios causados, no obstante que la víctima ha contribuido con su propia conducta a la generación del daño.

Por ello, intentaremos demostrar que tan grave deficiencia puede ser subsanada con un mínimo esfuerzo por parte de nuestros tribunales, analizando brevemente los distintos criterios que se han propuesto por la doctrina y el derecho comparado para resolver el problema, realizando una alusión al criterio que mayoritariamente siguen nuestros tribunales y desarrollando un breve análisis de la alternativa de solución que se considera más apropiada, mostrando algunas de sus ventajas. ${ }^{1}$ Actualmente, la doctrina mayoritaria acepta que las consecuencias de un hecho ilícito se repartan entre el autor y la víctima, aunque no hay unanimidad respecto a como ha de efectuarse tal distribución. Para dar respuesta a esta interrogante, se han propuesto tres sistemas:

\footnotetext{
${ }^{1}$ Para un tratamiento exhaustivo de este problema es recomendable consultar el artículo del profesor Domínguez Águila, "El hecho de la víctima como causal de exoneración de la responsabilidad civil", en Revista de Derecho, U. de Concepción, No 136, abr-jun. 1966, pp. 29-54. A pesar de haber sido escrito hace ya cuatro décadas conserva su pleno interés (además del mérito, por prestarle atención a un problema prácticamente ignorado o no abordado satisfactoriamente en aquella época por nuestra doctrina). También resulta interesante el análisis que le dedica al tema el profesor José Luis Diez en su, a estas alturas, obligada obra de referencia: El daño extracontractual. Jurisprudencia y Doctrina, y la monografía publicada en España por la profesora María Medina Alcoz, La culpa de la víctima en la producción del daño extracontractual, Dyckinson, Madrid, 2003, quizá uno de los trabajos más completos dedicados a esta materia y que analiza en detalle los criterios enunciados en este comentario.
} 
a. El criterio de las cuotas viriles: Es una posición tributaria de la teoría de la conditio sine qua non; plantea la distribución del daño por partes iguales o viriles, fundándose en que cada uno de los que interviene en el hecho debe ser estimado como responsable del mismo. La aceptación de esta alternativa implica renunciar a establecer las circunstancias específicas que rodearon la producción del daño. Este sistema fue adoptado por la mayoría de la doctrina francesa, que lo calificaba como el más simple, lógico y justo, pues evita la compleja búsqueda del reparto de la responsabilidad, al efectuarlo de acuerdo al número de intervinientes en el hecho dañoso; además se adecua a la teoría de equivalencia de las condiciones; y finalmente obliga a reparar el daño en proporción a su causación.

b. El criterio de las cuotas equitativas: Sostiene que las cuotas causales deben ser determinadas de manera equitativa por el juez, de acuerdo a su prudente arbitrio, puesto que las culpas no pueden ser valoradas ni comparadas. Del análisis efectuado por el profesor Diez Schwerter se concluye que nuestros tribunales siguen este criterio, con un ámbito exagerado entregado a la decisión del juez, que llega a lindar con lo arbitrario. ${ }^{2}$ Por este motivo, el profesor Domínguez Águila ha afirmado que, si bien la facultad judicial de apreciación no puede gobernarse por principios rígidos (propios de las ciencias exactas) tampoco es conveniente otorgarla con enorme amplitud, de manera que deben fijarse los criterios que el juez ha de seguir para fundamentar sus soluciones, limitando así su arbitrio personal.

c. El criterio de las cuotas proporcionales: Como su nombre lo indica, este sistema propone que las cuotas se establezcan proporcionalmente. Para algunos, la fijación de tal proporción debe ser subjetiva, fundándose en la gravedad de las culpas concurrentes; en cambio, para otros, el criterio ha de ser objetivo, basado en la entidad causal de las conductas en la producción del resultado dañoso. De acuerdo al primero de estos subcriterios, es la mayor o menor gravedad de las culpas de agente y damnificado la que determina el daño que debe indemnizarse por el agente (cuotas causales de culpa); para el segundo, es la menor o mayor participación causal de agente y víctima en el resultado dañoso la que fija el daño que ha sido ocasionado por aquél (cuotas estrictamente causales).

El primer subcriterio propone el prorrateo del daño considerando la gravedad de la culpa de cada uno de los sujetos intervinientes: cuanto mayor sea su gravedad, más amplia será su responsabilidad y, en consecuencia, soportará una porción mayor del resultado dañoso. Pues bien, si cada uno debe responder del daño que efectivamente ocasionó, el criterio de la gravedad de las culpas no es útil, e incluso podría llevarnos a consecuencias abiertamente injustas, pues es muy probable que la culpa más grave sea la menos influyente en la generación del perjuicio.

El subcriterio de las cuotas estrictamente causales propugna que cada cual debe soportar el daño en la medida en que lo haya ocasionado, puesto que se trata de un problema

${ }^{2}$ Diez, J. L., El daño extracontractual. Doctrina y Jurisprudencia, Editorial Jurídica de Chile, Santiago, 1997 , p. 236. 
de relación de causalidad y no de culpa. Debido a esto, el principio de causalidad debe prevalecer en el establecimiento de la extensión de la reparación, considerando que ante la ausencia de norma que imponga una solución determinada existe un espacio amplio de arbitrio judicial en vistas a establecer la distribución del daño entre las partes.

Esta alternativa de solución es seguida por la mayor parte de la doctrina contemporánea, ya que se ajusta más apropiadamente a la teoría de la causalidad adecuada y a la finalidad de la responsabilidad civil, que es la reparación del daño y no la punición, en consecuencia, es la cuantía del perjuicio y no la entidad subjetiva de la falta la que debe determinar el quantum indemnizatorio.

Considerando lo expuesto, se concluye que la solución más apropiada es que las cuotas de aportación causal de agente y víctima se calculen en atención a su poder genético en la generación del resultado dañoso, ya que ésta es la única alternativa con que la finalidad resarcitoria, propia de la responsabilidad civil, se cumple cabalmente, al comprender toda clase de causación, ya sea culpable o no culpable.

Resulta más lógico y justo distribuir la responsabilidad atendiendo a la influencia causal de cada culpa en la generación del daño. El demandado respondería del perjuicio en la proporción en que su culpa lo ha ocasionado. La víctima soportaría la fracción que corresponde a la eficacia causal de su hecho culpable. ${ }^{3}$

Pero seguir este criterio exige aceptar una teoría sobre la causalidad muy distinta a la equivalencia de las condiciones. Es necesario admitir el principio de que no todas las condiciones que concurren a la producción de un daño tienen aptitud para generarlo en una misma medida.

Una vez formulada esa conclusión, se hace necesario representar que no es conveniente otorgar facultades tan amplias a los jueces en esta materia. Debe proporcionárseles algún principio que facilite su tarea y que concrete las exigencias de certeza y justicia. Está claro que en un problema tan relativo y complejo como éste, los tribunales requieren de una facultad amplia de apreciación, ya que, como se ha dicho, es imposible fijar principios rígidos, propios de las ciencias exactas. Sin embargo, tampoco es apropiado no fijar ningún criterio. Y el principio de distribución de responsabilidad por la influencia causal es el más conveniente. Tal como lo puso de manifiesto el profesor Domínguez Águila, hace ya décadas, en su excelente artículo, la responsabilidad civil aspira a reparar el daño causado y en la medida en que se ocasionó, resultando evidente que no todos los hechos que han generado el perjuicio contribuyen en igual proporción a producirlo. Algunos son más determinantes que otros. Es de justicia, por tanto, supeditar la distribución de la responsabilidad a la influencia causal. ${ }^{4}$

En definitiva, el criterio de las cuotas estrictamente causales concuerda con la equidad y con la finalidad perseguida por la responsabilidad civil. Ciñéndose a él, se evita caer en el misterio no revelado por estas y otras sentencias.

${ }^{3}$ Vid. Domínguez Águila, R., "El hecho de la víctima como causal de exoneración de responsabilidad civil”, en Revista de Derecho y Ciencias Sociales, U. de Concepción, No 136, 1966, p. 45.

${ }^{4}$ Ibid., p. 47. 